\title{
Application of Ground-Penetrating Radar for Specifications of Blasting Rocks
}

\section{Boris Vladimirovic Ekvist, Roman Leonidovic Korotkov}

Department of Physical Processes of Mining Production, The National University of Science and Technology "MISiS”, Moscow, Russia

Email address:

borisekwist@mail.ru (B. V. Ekvist)

\section{To cite this article:}

Boris Vladimirovic Ekvist, Roman Leonidovic Korotkov. Application of Ground-Penetrating Radar for Specifications of Blasting Rocks. International Journal of Mineral Processing and Extractive Metallurgy. Vol. 4, No. 1, 2019, pp. 14-17. doi: 10.11648/j.ijmpem.20190401.13

Received: February 21, 2019; Accepted: March 28, 2019; Published: April 18, 2019

\begin{abstract}
Proposed a method for optimizing the parameters of drilling and blasting operations, considering the physical and technical properties of rocks within the blasted block, in order to improve the quality of the blasting quarries with a complex geological structure. Described the ground-penetrating radar method is with the application of the "Oko-2" series of the development of the group of companies "LOGIS-GEOTECH" with antenna blocks AB-90 with a depth of sounding up to $16 \mathrm{~m}$. and a resolution of $0.5 \mathrm{~m}$. in depth and AB-150 with a sounding depth of $12 \mathrm{~m}$. and resolving ability of $0.35 \mathrm{~m}$. in depth. The results of laboratory experiments carried out on blasting blocks with various strength properties are presented, confirming the improvement in the quality of crushing of rock samples by explosion of charges with variable decelerations and location, depending on the strength properties of the samples, relative to charge explosions with unchanged parameters. This will ensure a better crushing of the blasted rock mass.
\end{abstract}

Keywords: Drilling and Blasting Operations, Ground-Penetrating Radar, GPR, Complex-Structured Rocks

\section{Introduction}

Blasting destruction of complex-structured rocks has a several of features related to the strength properties. To optimize drilling and blasting operations of complexstructured rocks requires an assessment of the physical and engineering properties of rocks and the determination of the coordinates of their location with different strength properties inside the blocks. The method of ground-penetrating of the surface layer with the use of ground-penetrating radars is suitable for the rapid assessment of the physics-technical properties of blasted blocks. Ground-penetrating radars (GPR) technologies can be used for detailed researching of complex structure arrays, as well as for determining the coordinates of bedding of rocks with different strength properties $[1,2]$. Since optimizing the parameters of drilling and blasting operations and selecting the necessary grid sizes for the location of charges and delay interval. With a smooth change in the strength and cracking of the rock, the drilling and blasting works parameters change smoothly, with jumpdifferent - jumpwise. It is known that solid rock characteristics affect the location of charges on the blast block and the delay interval. For example, if the strength of explosive rocks decreases, according to existing recommendations, the explosions delay are increase, and the distances are decrease [3-5].

\section{Ground-Penetrating Radar}

\subsection{Principle of Operation}

The features of ground-penetrating radar are the efficiency of the work being carried out and the possibility of obtaining non-discrete data on the rocks. To implement this method, a radar is used - a geophysical device for researching the exploded array. This is the modern technique for geological researching not requiring drilling or excavation. Carrying out of geological researches, at construction profile a ground, based on drilling of boreholes with the certain step, does not give an exact estimation of local objects.

The method of ground-penetrating radar is based on the reflection of electromagnetic wave from rocks with different properties as electrical conductivity and dielectric permittivity. The reflected signal is received by the receiving antenna and transformed into a digital format.

The main value in ground-penetrating radar research is the 
time of passing an electromagnetic wave from the source to the reflecting boundary and back to the receiver. Since the propagation velocity of the electromagnetic wave in different materials a different, measuring the travel times of the waves, and knowing the basic physical properties of the rocks in the investigated medium, one can judge the structure of the rocks.

The main purpose of the ground-penetrating radar method is to determine the position of the boundary or local objects. When the GPR antenna is moving along the profile, a radargram is recorded for the depth and movement of the antennas along the block (Figure 1).

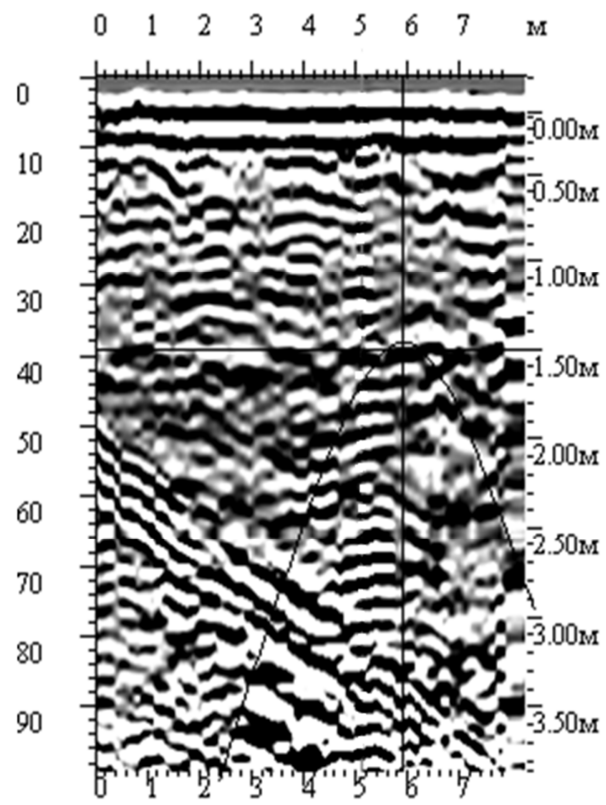

Figure 1. GPR tracking, an example of a radiogram. GPR "OKO-2" series, antenna unit $A B-400$

The main parameters that determine the shooting technique, and accordingly the choice of antenna blocks: are the necessary depth of research, resolving ability and the size of the structural elements (layers or local objects) that need to be identified. In accordance with these values, antenna units with a certain depth of sounding and resolving power are selected.

The depth of sounding is the maximum depth of the reflecting object. For example, if the task is to determine the location of an object located approximately at a depth of $3 \mathrm{~m}$. it can be detected with the aid of antennas, the depth of sounding of which exceeds a predetermined depth.

Resolving ability is the minimum depth distance, on which two reflecting objects or their parts can be distinguished. In practical terms, to successfully solve the problem, it is necessary that the thickness of the layers exceed the value of the depth resolution for the selected antenna.

\subsection{Russian GPR Using}

Widely spread in Russia got ground-penetrating radars of the company "LOGIS" of the series "OKO". They are characterized by a wide range of provided basic and auxiliary equipment. Antenna unit includes in its composition receiving and transmitting antennas, transmitting and receiving devices and information processing systems. The type of the antenna unit determines the depth of sounding and the resolving power of the GPR. The device can be equipped with several antenna units for different tasks. Block processing, management and display, usually laptops of various types with the operating system Windows.

The antenna blocks of the "Oko-2" are replaceable. It is consists of a receiving and transmitting unit. The processing of sounding data is carried out by the program "GeoScan 32".

The principle of processing consists in the allocation of a useful signal against a background of noise and the decoding of radargram. Through a variety of signal conversion techniques, interference is attenuated or deleted from the recording, and useful signals are allocated. In the process of interpreting radargram, the boundaries of layers in the stratum are distinguished.

For this method to be implemented in industry, it must have a significant economic effect and be sufficiently technological. This is especially important for quarries where the differences in the strength properties of rocks.

The method includes the following basic operations:

1. in accordance with the required depth of research and the size of the structural elements, an antenna unit with a certain depth of sounding and resolving ability is selected;

2. when moving the GPR antenna unit along the profile, images is performed;

3. when geological information is used about existing rocks in the field, the obtained diffraction images are linked to the structure of the blast block;

4. based on the obtained data on the geological structure of the block, the parameters of the drilling and blasting operations are selected depending on the strength characteristics of the parts of the blasted block.

\section{Experiment}

To test theoretical studies the blasting effect on complexstructure arrays, characterized both by the smooth transition of rocks from one strength to another, and by the presence of solid inclusions there, experiments were carried out on simulated different-strength blocks measuring $40 \times 30 \mathrm{~cm}$ and thick-plane $4 \mathrm{~cm}$. The location of charges in which is shown in figure 2. The distance between the charges in blocks which not considering the strength properties, on the larger side of the block $20 \mathrm{~cm}$ and at the side of the block $15 \mathrm{~cm}$. The distances between the charges changed and considering the strength characteristics of the blasting blocks, are shown in figure 2 on a scale relative to the dimensions of the blasting blocks. The number of charges varied depending on the strength characteristics and the structure of the blasting blocks. The unpainted parts of the blocks had a coefficient of strength on the scale of professor M. M. Protodiakonov $1.5-2$, and painted 2.5 - 3. Models of blocks were made of dry quartz sand with particles not larger than $0.25 \mathrm{~mm}$ with addition of gypsum and water in various proportions. 
a

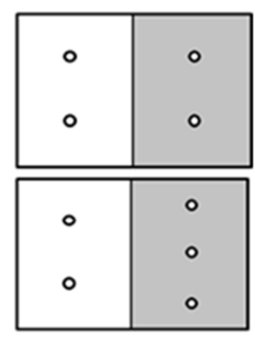

c

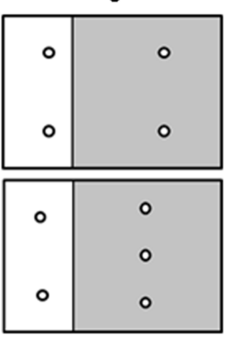

b

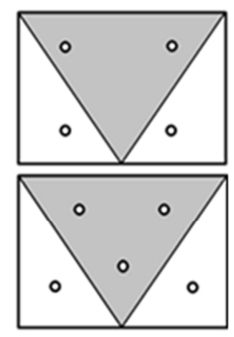

$\mathrm{d}$

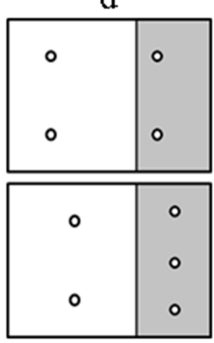

Figure 2. Schemes of explosion of model blocks, consisting of different rocks with the same strength, with unchanged parameters of the location of charges (upper row) and changed distances between charges, considering the strength characteristics of the blocks (bottom row).

Explosions of models carry through by a five-channel pulse generator with the use of delayed blasting by discharging capacitors to pyrotechnic fuses [6].

The maximum voltage to generator is charged on $260 \mathrm{~V}$. The capacity in each one of the five channels is $3000 \mu \mathrm{F}$. The residual voltage after simulating an explosion is $50 \mathrm{~V}$. The energy released when a capacitor is discharged from one channel in a five-channel generator:

$$
\begin{gathered}
W_{\text {exp }}=\frac{C U^{2}}{2}-\frac{C U_{r e m}^{2}}{2}, J \\
W_{\text {exp }}=\frac{3000 \cdot 10^{-6} \cdot 260^{2}}{2}-\frac{3000 \cdot 10^{-6} \cdot 50^{2}}{2}=97,65 \mathrm{~J}
\end{gathered}
$$

where:

$W_{\text {exp }}$ - the energy released during the simulation of the explosion, J;

$C$ - capacitance of capacitor $\mathrm{F}$;

$U$ - the voltage to the capacitor is charged $\mathrm{W}$;

$U_{\text {rem }}$ - voltage that remained on the capacitors after simulating the explosion, $\mathrm{W}$.

The energy released can be reduced by lowering the voltage to which capacitors are charged. To increase the explosion power of a single charge, each capacitor was expanded to a pyrotechnic fuse inserted into the hole of the model unit. Then the power of explosion of a single charge:

$$
W=W_{b l s t}+W_{\text {pyro }}=97.65+300=397.65 \mathrm{~J}
$$

where:

$W_{\text {pyro }}=300-$ explosion energy of a pyrotechnic fuze, $\mathrm{J}$.

The total maximum energy $\mathrm{W}_{\text {total }}$, which was obtained in simulating the explosion:

$$
W_{\text {total }}=5 \times 97.65+5 \times 300=1988.25 \mathrm{~J}
$$

In order to make the experiment in laboratory conditions close to field studies, explosions in the less stable part of the blocks occurred simultaneously in the first place, and then in $5 \mathrm{~ms}$ there were simultaneous explosions in a more solid part of the model blocks.

Laboratory studies include three series of experiments with varying variations in the strength characteristics of the block models. In each series was made two models of blocks. First one it was blasted by charges are not considering of physicaltechnical property. Second one it was blasted be charges considering changed property (distance between the charges, quantity and $5 \mathrm{~ms}$ delay)

In the first series of experiments (figure 2a), the interface of the rocks passed along the center of the block. In the second (figure $2 b$ ), the hard rocks were located inside the model in the form of a wedge, but weak on the sides. The wedge of solid rocks in the sample imitated the chaotic arrangement of inclusions of solid rock within the rock massif. In the third series of experiments, (figures $2 \mathrm{c}$ and $2 \mathrm{~d}$ ), the interface of the rock strength was shifted in one case toward strong rocks, and in the other is toward the weak.

According to the experimental data, the quality of rock crushing was assessed. The output of coarse fractions and the average size of pieces of crushed samples were taken as criteria for the efficiency of crushing.

Such variations in the arrangement of solid rocks in the samples simulating the complex-structural explosive massif made it possible to estimate the efficiency of the drilling and blasting parameters change depending on the geometry of inclusions and the volume of destruction of strong and weak rocks. Since the strength characteristics of the rocks affect the choice of blasting parameters, these parameters will directly depend on the change in the properties of the rocks. That is, if the property change occurs smoothly, then the parameters change smoothly, and if the property change is sharp, the parameters change in an abrupt manner. If solid inclusions are present in the rock massif, it is necessary to place the charges so that the line of least resistance to the rock boundary corresponds to the radius of the controlled crushing $[7,8]$.

As a result of the experiments, it was established that when samples are blasted, considering the changing properties of the block rocks, and, correspondingly, with the change in the drilling and blasting parameters, cracks and chips are formed in the weak rocks passing along the boundary between the rocks of different strength. This facilitates the unloading of strong rocks and facilitates the destructive effect of explosions of charges in them. Thus there is a more intensive crushing of hard rocks in arrays with a complex geological structure [9-11].

Figure 3 compares the yield of large fractions in the explosion of weak and strong rocks during the explosion of experimental blocks not considering and considering the changing properties of the rocks. Obviously, in the second case, the efficiency of crushing is higher than in the former. At the same time, the efficiency of crushing in solid rocks increases, the yield of large fractions decreases by $26 \%$. Also, 
when the parameters of blasting operations change, a more uniform crushing of both weak rocks and strong inclusions is observed and the yield of medium fractions increases.

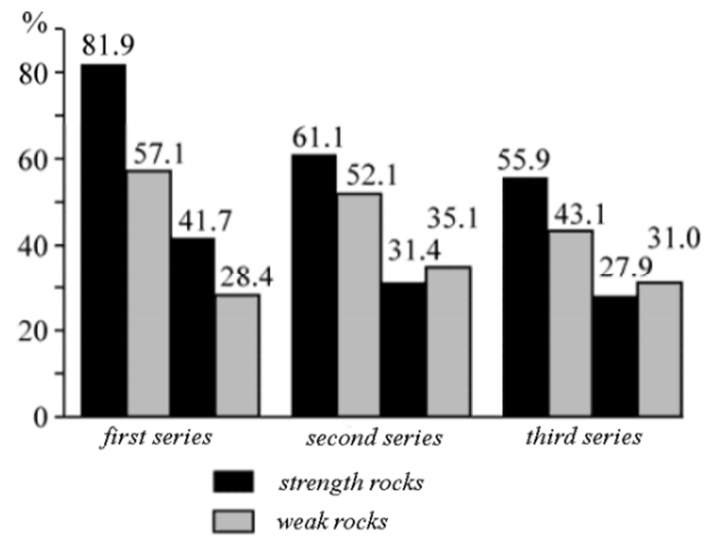

Figure 3. The histogram of the output of large fractions depending on the properties of the samples: the first two columns with invariable parameters of the explosion, the two following - with the modified.

With a gradual change in properties, it is necessary to considering the gradient of their variation in the space. The picture of the change in the properties of the exploded rocks can be compiled on the basis of GPR reference.

Figure 4 shows the breakdown of the exploded block by charges of explosives. The points $A, B, C, B, M, K$ are the location of the charges. Assume at point $A$ the strength $f$, it corresponds to the distance between the well charges $a$ and the deceleration $t$. We divide the distance $a$ along the $y$ axis, and also the distance $a$ along the $x$ axis. At point $B f$ strength $f_{l}$, it corresponds to the distance between charges $a \pm \Delta a$. Plus, if the strength $f 1 \leq f$, minus if $f_{1}>f$. Deceleration between points $B$ and $B-t \pm \Delta t$. Plus, if the strength $f_{l} \leq f$, minus if $f_{1}>f$. Analogously at the point $C$, the strength $f_{2}$, it corresponds to the distance between the charges $a \pm \Delta a_{1}$. Plus, if the strength $f_{2} \leq f$, minus if $f_{2}>f$. The slowing down between points $C$ and $M$ is $t \pm \Delta t_{1}$. Plus, if the strength $f_{2} \leq f$, minus if $f_{2}>f$. The values of $\Delta a, \Delta a_{1}$ and $\Delta t, \Delta t_{l}$ are the larger, the larger the gradient of the rock bredness. For the following points $B, K, M$, etc. the actions are the same.

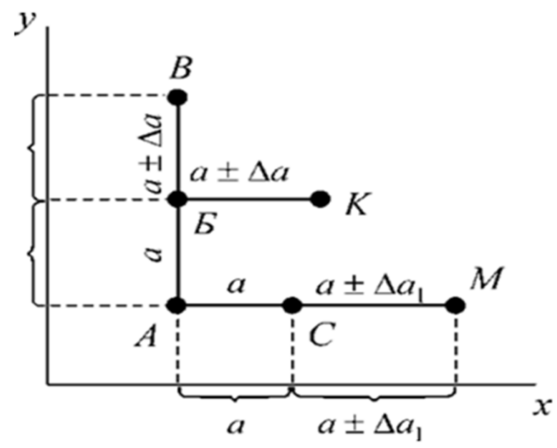

Figure 4. Breaking of an exploded block with explosive charges.

\section{Conclusion}

As a result of changes in the parameters of blasting operations within the destroyed blocks (location of charges, sequence of blasting, delay interval), in accordance with the changing physical and technical properties of rocks, it is possible to achieve a more qualitative crushing than unchanged parameters.

The performed laboratory experiments confirm the efficiency of changing the parameters of drilling and blasting operations, depending on the geological features of the inhomogeneous massif.

A technique for blasting rock massifs based on their GPR spreads is proposed.

\section{References}

[1] Kulizhnikov, A. M., Burda, S. N., \& Belozerov, A. A. Primenenie georadarov dlya razvedki i otsenki zapasov dorozhno-stroitel'nykh materialov. Gornyy Zhurnal, Moscow. 2004, №3, P. 86-87.

[2] Semeykin, N. P., Pomozov, V. V., Ekvist, B. V., \& Monakhov, V. V. (2008). Geofizicheskie pribory novogo pokoleniya. Gornyy Informatsionno-Analiticheskiy Byulleten’, 2008, №12. P. 203-210.

[3] Kutuzov, B. N. Metody vedeniya vzryvnykh rabot. Razrushenie gornykh porod vzryvom. Moscow. Gornaya kniga. 2009. 471p.

[4] Gorokhov N. L. The mathematical formulation and numerical implementation of dynamic problems of geomechanics using finte element method // Scientfic Reports on Resource Issues. Vol 1. Internaational University of Resources Frierberg 2011. P. 205-211.

[5] Alenichev, I. A. Korrektirovka udel'nogo raskhoda vzryvchatogo veshchestva. Gornyy InformatsionnoAnaliticheskiy Byulleten, 2016, №7, P. 364-373.

[6] Ekvist, B. V., \& Vartanov, V. G. Laboratornyy praktikum po distsipline "Tekhnologiya i bezopasnost' vzryvnykh rabot". Moscow: Gornaya kniga, 2006, 50 p.

[7] Chan Kuang Hiyeu, Nguyen Din Ahn, Nkhy Van Fuk, Belin V. A. Pilot studies of influence of diameter of explosive wells on seismic action of explosions on Nuybeo coal mine. Explosive technologies: conference materials, Hanoi, Vietnam. 2015, P. 252-255.

[8] Ekvist B. V., Gorbonos M. G. Improving the safety of seismic manifestations of short-term explosion in mining enterprises. M.: Mountain journal. 2016, №10, P. 34-36.

[9] Ekvist B. V. Theory of combustion and explosion. Textbook, Moscow. MISIS, Russia. 2018, 179 p.

[10] Kutuzov, B. N., Ekvist, B. V., \& Bragin, P. A. Sravnitel'naya otsenka seysmicheskogo vozdeystviya vzryva skvazhinnykh zaryadov pri ispol'zovanii sistemy neel- ektricheskogo initsiirovaniya i elektrodetonatorov $\mathrm{s}$ elektronnym zamedleniem. Gornyy Zhurnal. 2008, №12, P. 44-46.

[11] Mehdi Hosseini, Mehdi Seifi Baghikhani. Analysing the Ground Vibration Due to Blasting at AlvandQoly Limestone Mine// International Journal of Mining Engineering and Mineral Processing, 2013, № 2 (2), P. 17-23. DOI: 10.5923/j.mining.20130202.01. 